\title{
MULHERES A FERRO E FOGO: REFLEXÕES SOBRE A MUSEALIZAÇÃO DO CANGAÇO
}

Marking women with branding irons: reflections about the musealization of the "cangaço"

Clovis CARVAlHo BRitTO

http://dx.doi.org/10.1590/S0103-21862016000100004

Clovis Carvalho Britto é doutor em Sociologia pela Universidade de Brasília e professor do Departamento de Museologia e do Programa de Pós-Graduação em Antropologia da Universidade Federal de Sergipe (clovisbritto5@hotmail.com).

Artigo recebido em 21 de dezembro de 2015 e aprovado para publicação em 10 de março de 2016. 


\title{
RESUMO
}

Este artigo examina alguns itinerários de musealização de um "evento crítico" que atravessa o campo da história, museus e patrimônios no Brasil: o cangaço. Visualiza como um cruzamento de "eventos críticos" gera discursos polêmicos amalgamados na violência, morte e dor. 0 objetivo é destacar aspectos da trajetória do cangaceiro José Baiano e da violência contra as mulheres para, em seguida, problematizar as memórias e silêncios dessas narrativas em exposições museológicas. Analisa a musealização dos ferros de marcar e das fotografias de mulheres que tiveram os rostos violentados como tema para refletir sobre a construção de discursos em quatro museus brasileiros.

PalaVras-CHAVE: musealização; eventos críticos; cangaço.

\begin{abstract}
This paper examines some itineraries of the musealization of a "critical event" present in the field of history, museums and heritage in Brazil: the "cangaço". It observes how a crossing of "critical events" generates controversial speeches amalgamated in violence, death and pain. The aim is to highlight aspects of the trajectory of the "cangaceiro" José Baiano and of the violence against women and discuss the memories and silences of these narratives in museum exhibitions. It analyses the musealization of branding irons and photos of women who have had their faces violated as a motto to reflect on the construction of speeches in four Brazilian museums.
\end{abstract}

KEYwORDs: musealization; critical event; cangaço.

\section{RÉSUMÉ}

Cet article examine quelques itinéraires de muséalisation d'un "événement critique" qui traverse le champ de I'histoire, les musées et les sites patrimoniaux au Brésil: le "cangaço". On observe comment un croisement d'"événements critiques" produit des discours controvers amalgamés dans la violence, la mort et la douleur. L'objectif est de mettre en évidence des aspects de la trajectoire du "cangaceiro" José Baiano et de la violence contre les femmes et de discuter les mémoires et les silences de ces récits dans les expositions des musées. On analyse la muséalisation des fers à marquer et des photos de femmes qui ont eu leur face violée dans le but de réfléchir sur la construction de discours dans quatre musées brésiliens.

MotS-CLÉs: muséalisation; événements critiques; "cangaço". 


\section{A musealizaÇÃo de "EVEnTOS CRíticos"}

1 categoria "evento crítico" se relaciona à linguagem do sofrimento e à experiência trau(Das, 1995). Embora possível de ser aplicada em diferentes espaços sociais e simbólicos, nosso interesse é analisá-la nas exposições museológicas que privilegiam a patrimonialização da dor e a musealização de situações traumáticas.

Nesse sentido, dialogamos com Telma Camargo Silva quando problematizou que, se os eventos críticos "não são pontuais e sim resultados de um processo em que alinhamentos sociais e o mundo simbólico são construídos e reconstruídos historicamente" (2010: 24), as demandas sobre essa patrimonialização contribuem para uma maior compreensão das memórias e das relações de pertencimento elaboradas em torno dessas configurações:

No processo da vivência desses eventos e das rupturas por eles causadas, a produção da memória é um dos elementos significativos para a apreensão do significado por eles engendrados. No jogo da lembrança e do esquecimento pertinente à produção da memória, diversas narrativas produzidas sobre os eventos críticos articulam, de um lado, o discurso oficial e, de outro, as múltiplas narrativas trazidas pelos sobreviventes. Em muitos casos, as lembranças apontam para a contínua repetição do drama vivido, sinalizando que o rito de passagem, performativo da superação do trauma e do terror, não foi ainda vivenciado, persistindo a condição de vitimização. Em outros, os processos narrativos formulam novas identidades fortalecidas pelo empoderamento advindo da perspectiva assumida de agência em face do drama (Silva; Souza; Eckert, 2011: 269).

No caso dos museus, na medida em que contribuem para fabricar e projetar versões específicas sobre fatos, personagens e objetos, eles impõem a sua própria narrativa "aberta à leitura, mas resistente às interpretações que a desvirtuem, que rasurem ou alterem a imagem instituída" (Cunha, 2003: 125), selecionando eventos passados de acordo com as estratégias formuladas no presente. Mário Chagas, ao parafrasear Mário de Andrade evidenciando a existência de "uma gota de sangue em cada museu", destaca uma veia poética e uma dimensão humana que reconhece os museus "como arena, espaço de conflito, como campo de tradição e contradição" (Chagas, 2006: 30). Questão evidente quando nos deparamos 
com a musealização de "eventos críticos" que, por sua vez, são forjados a partir de diversas e divergentes narrativas, nas tensões em prol da legitimidade de determinadas versões.

De acordo com Izabela Tamaso, o conflito é inerente às políticas de preservação dos patrimônios culturais. Ancorada nas formulações de Lowenthal que defendem ser o conflito "endêmico ao patrimônio", afirma ela que os valores atribuídos aos bens culturais quando entram em disputa sofrem uma hierarquização: "um valor será selecionado como mais importante e mais legítimo; os outros permanecerão como seus opostos complementares: valor artístico/valor da fé", reconhecendo que o grupo que "estiver de posse da gestão daquele bem cultural estabelecerá seus valores como mais legítimos. Na arena de disputa, os outros não poderão ser considerados" (Tamaso, 2005: 15).

Portanto, se os conflitos são inerentes às práticas patrimoniais, a patrimonialização de "eventos críticos" se torna um exemplo extremo dessa argumentação devido à própria dor/ trauma sustentar o discurso de sua fabricação/monumentalização. Surge, assim, um campo de forças em torno de múltiplas narrativas e interesses, a partir de processos de atribuição de sentido e um sistema classificatório que é instrumento de poder.

Nesse aspecto, é fundamental reconhecermos os museus como um dos elementos constitutivos dessas práticas, espaços de poder legitimadores de narrativas, promotores de discursos e controladores de versões concorrentes, compreendendo que as memórias selecionadas não são neutras. Os "eventos críticos" consistem em exemplos de situações traumáticas que, manipuladas, tornaram-se sintomáticas na trama da economia simbólica que constrói o patrimônio cultural brasileiro visualizado, por exemplo, no campo museal.

0 interesse crescente pelas narrativas de "eventos críticos" e pelos objetos a eles associados dialoga com a perspectiva de que o acervo revelaria uma pretensa intimidade ou uma faceta mais "verdadeira" dos agentes envolvidos. Atravessadas pela marca da personalidade de seu titular, as coleções e as memórias da dor provocam aquilo que Ângela Gomes (1998) denominou um "feitiço": encantamento acionado pelo conjunto de fontes outrora inacessíveis ao grande público, gerador de ilusões de espontaneidade, verdade e autenticidade. Feitiço alimentado pela sistemática da economia dos bens simbólicos com vistas a envolver cada vez mais agentes ávidos por consumir esse tipo de informação avalizada pela assinatura (lato sensu) do personagem musealizado e fabricada socialmente, por exemplo, nos processos museais.

Os museus constituem importantes espaços de produção simbólica, difundindo narrativas imbricadas com as noções de lembrança e esquecimento, silêncio e fala, preservação e destruição, tornando-se, assim, espaços de poder. As exposições museológicas são uma das principais funções do museu, "lugar por excelência da apresentação do sensível" 
(Desvallées; Mairesse, 2013: 43), constituindo-se em mecanismo cuja proposição constrói (e/ ou desconstrói) as memórias do poder e os poderes da memória.

Ao proporem determinadas narrativas a respeito de "eventos críticos", as exposições museológicas traduzem "nós de memória" em testemunhos, na necessidade de contar aos outros e também torná-los, de certo modo, participantes. Daí a importância de visualizarmos o "entre-lugar" ocupado pelas exposições ao se transformarem na narrativa de uma narrativa traumática, entre o trabalho individual de reconstrução do trauma e sua componente coletiva, ou seja, o trauma encarado como "a memória de um passado que não passa":

A imaginação apresenta-se a ele como o meio para enfrentar a crise do testemunho. Crise que, como vimos, tem inúmeras origens: a incapacidade de se testemunhar, a própria incapacidade de se imaginar, o elemento inverossímil daquela realidade ao lado da imperativa e vital necessidade de se testemunhar, como meio de sobrevivência. A imaginação é chamada como arma que deve vir em auxílio do simbólico para enfrentar o buraco negro do real do trauma. 0 trauma encontra na imaginação um meio para sua narração (Seligmann-Silva, 2008: 70).

Reconhecendo que a narrativa sempre será parcial, um arremedo dos fatos, uma forma de negociação com o exposto, torna-se oportuno reconhecer, no caso da memória trauma reconstruída no campo da produção cultural - e aqui especificamente nas exposições museológicas -, sua afirmação da necessidade de narrar o fato justificando esse gesto como:

1) um impulso para se livrar da carga pesada da memória do mal passado; 2) como dívida de memória para com os que morreram; 3) como um ato de denúncia; 4) como um legado para as gerações futuras; e, finalmente, 5) como um gesto humanitário na medida em que o testemunho serviria como uma memória do mal. Os eventos narrados são apresentados como exemplo negativo visando prevenir, de algum modo, a repetição deste tipo de terror (Seligmann-Silva, 2009: 9).

Os museus se apresentam como uma das formas de encenação dessa memória, visto que o colecionismo "está de algum modo associado ao medo da morte ou à necessidade de se manter vivo, em memória, através dos objetos colecionados, sejam eles quais forem. (...) Um indivíduo estará realmente morto quando ninguém mais se lembrar dele" (Queiroz, 2014: 49). No caso de "eventos críticos", a musealização torna-se um estratagema, uma tentativa de narrar o inenarrável. Nesses termos, dialogamos com a problematização de Cristina Bruno quando reconhece que a Museologia pode orientar e organizar "as formas de perseguição ao abandono e tem a potencialidade de minimizar os impactos socioculturais do esquecimento a partir dos processos de musealização que, por sua vez, educam para o uso qualificado do patrimônio" (Bruno, 2000: 2). 
De acordo com esse entendimento, optamos por examinar alguns itinerários da musealização de um "evento crítico" amplamente difundido no campo da história, dos museus e dos patrimônios no Brasil: o cangaço. Visualizamos essa história como um atravessamento de "eventos críticos" que geram discursos controversos justamente por se amalgamar na violência, na morte e na dor. 0 intuito é destacar facetas da trajetória do cangaceiro José Baiano e da violência contra as mulheres no cangaço para, em seguida, problematizar tais narrativas em quatro exposições museológicas.

\section{Mulheres marcadas PElO CANGaÇO}

$\mathrm{O}$ cangaço consiste em um "evento crítico" significativo na configuração sócio-histórica brasileira. De acordo com José Murilo de Carvalho (2003), os cangaceiros eram bandidos sociais que reagiam à situação de desigualdade e arbítrio prevalecentes no sertão, mas que se utilizavam das mesmas táticas dos coronéis, sobretudo a violência. Lembranças sobre a violência, a resistência e a dor estão presentes nas histórias em torno de Lampião e Maria Bonita naquela região. Durval Muniz de Albuquerque Júnior (2011) apresenta os diferentes discursos construídos em torno do cangaço que impactaram e ainda impactam as invenções do Nordeste:

O Estado Novo pôs a funcionar toda uma maquinaria de esquecimento do cangaço. A grande imprensa é intimada a silenciar sobre seus feitos; a gritar, em grandes manchetes, o seu fim. Os cangaceiros, a partir desse momento, são tratados como criminosos comuns. Estes não passam de hostes de bandidos que ainda perambulam pelo sertão. (...) O silêncio se faz ouvir e o cangaceiro mergulha nas sombras para brilhar como 'símbolo de um passado', vencido pela ordem e pela civilização. Estes homens permanecem vivos, no entanto, na memória popular, nas produções culturais populares. 0 cangaceiro se torna um mito, no momento em que deixa de fazer história. Quando ainda estava em atividade, na década de trinta, sofria a condenação quase unânime dos intelectuais. Mesmo entre os tradicionalistas, o cangaceiro saudoso era o cangaceiro morto; era aquele que tinha vivido num passado idílico. (...) As narrativas e obras sobre o cangaço enfatizam o seu lado cruel, violento, selvagem, desenhando o Nordeste como o espaço da valentia e da morte estúpida e gratuita, por puro sadismo, por prazer, ou por espírito de vingança. (...) A leitura que a esquerda faz do cangaço se altera, na década de quarenta, exatamente no momento em que é anunciado seu fim. Passa a ser lido como um signo de rebelião, como um indício da possível revolta futura. A mitificação do cangaço se dá também por uma verdadeira postura voluntarista, pouco crítica e analítica das condições históricas e sociais do surgimento do cangaceiro. Este já não é vítima de uma sina, mas de uma sociedade. É, principal e simploriamente, vítima do latifúndio (Albuquerque Júnior, 2011: 230-232). 
Independentemente dos múltiplos e conflitantes discursos que apresentam os cangaceiros como heróis ou bandidos, é evidente que o cangaço consiste em um "evento crítico", visto que é construído sob o signo da violência, da opressão, da insegurança, da seca, da morte. 0 multifacetado conjunto discursivo em torno desse acontecimento torna-se significativo para a análise e a problematização de violências físicas e simbólicas, especialmente no que diz respeito à (in)visibilidade das mulheres, na maioria das vezes reconhecidas como coadjuvantes ou "silêncios da história", conforme a clássica expressão de Michelle Perrot (2005). Essa aproximação ganha fôlego na medida em que relatamos irrupções de presenças e de falas femininas em locais até então proibidos ou não familiares e que, ainda hoje, são envoltas por muitas "zonas mudas", relacionadas à partilha desigual dos traços, da memória e da história. Para tanto, concordamos com a autora quando afirma que esta reflexão não intenta modificar o lugar ou a "condição" destas mulheres, mas é um esforço para que possamos compreendê-las melhor e, indistintamente, compreender como a dominação masculina se "naturaliza" e rever a importância da atuação feminina (aparentemente embargada) na tessitura e na invenção de tradições.

Quando lembradas, as mulheres não receberam a mesma avaliação dispensada aos homens e seus nomes foram apenas citados entre uma exaustiva enumeração de autores, cortesia que reforça a ideia de excepcionalidade a uma regra masculina. Estas são questões que podem ser visualizadas nos estudos sobre o cangaço, cuja fortuna crítica ainda apresenta poucos trabalhos que examinam mais detidamente esse protagonismo. Nesse rol, quando problematizadas, a opção dos pesquisadores foi evidenciar a atuação das cangaceiras (cf. Araújo, 2012; Ferreira, Araújo, 2011; Freitas, 2005).

Nosso intuito neste trabalho é evidenciar as mulheres violentadas pelo cangaceiro José Aleixo Ribeiro da Silva, alcunhado de José Baiano. Ao iluminarmos esse episódio - "evento crítico" específico que integra o "evento crítico" cangaço - deslocamos o foco de análise para a evidência da violência física e simbólica contra as mulheres, ao mesmo tempo em que abrimos caminho para a problematização da musealização deste acontecimento em quatro museus brasileiros.

De acordo com Luiz Bernardo Pericás (2010), alguns cangaceiros tentavam impor sua autoridade por meio de punições e torturas corporais similares às utilizadas no período da escravidão. Sublinha o autor que práticas como açoites, castrações, amputações, "sangramentos" e marcação em ferro em brasa das pessoas, como animais, comuns no Brasil Colônia e no Império, foram recuperadas pelo cangaço. 0 pesquisador reconhece que, quando ferravam, os cangaceiros não apenas puniam, mas enviavam a mensagem de que eram "donos" das pessoas marcadas, reproduzindo práticas do período escravocrata: 
Antes mesmo de serem embarcados para o Brasil, os negros negociados na África eram carimbados com ferro incandescente, como bois, em diferentes partes do corpo (coxa, braço, ventre, costas, peito ou face) com o sinal do consignatário (o novo proprietário), para facilitar a entrega da 'mercadoria', quando essa fosse desembarcada nos pontos brasileiros. A marca de ferro, nesse sentido, não seria tanto um castigo como uma necessidade de caráter comercial e econômico, uma formalidade mercantil dentro do tráfico negreiro. 0 mesmo ocorria com os escravos indígenas. Um alvará do Rei D. João $V$, de 1741, ainda ordenava que os escravos fugidos que fossem capturados tivessem marcados a ferro a letra 'F' nas costas. Até o século XIX esse procedimento continuou sendo comum no território nacional, uma forma de o fazendeiro identificar e garantir a posse de sua 'propriedade', assim como igualmente uma 'punição'. Um anúncio do Diário do Rio de Janeiro, de dezembro de 1825, divulgava: 'Em 25 de dezembro passado, fugiu um preto ainda rapaz, de nome Joaquim, de 14 a 15 anos de idade, bonito e muito retinto, tem nos peitos as letras F. C. entrelaçadas'. Outro 'classificado', no mesmo periódico, dessa vez de 16 de outubro de 1826, informava que 'um moleque fugido a 2 de maio de 1826, por nome Luís, entre 10 e 12 anos apenas, no peito esquerdo tem uma marca F. M. P. junta, e pouco se percebe, que é o carimbo com que ele foi marcado' (Pericás, 2010: 103-104).

No cangaço essa prática foi recuperada por José Baiano, cangaceiro do bando de Lampião. Segundo informações apresentadas por José Bezerra Lima Irmão (2014), José Baiano nasceu nas Areias, atual Macururé (BA), filho de Teodora e Faustino Ribeiro da Silva, pertencente à família dos Engrácia, nome de sua avó, sendo primo dos cangaceiros José Sereno, Mané Moreno, Antônio de Seu Naro e Sabonete. 0 pesquisador informa que ele teria se juntado ao bando de Lampião inicialmente em setembro de 1926, desligando-se dois meses depois e reincorporando-se de modo definitivo em 1929. Destaca ainda o episódio da mutilação nos rostos de três mulheres com a marca "JB", em fato ocorrido em 1932 na cidade de Canindé de São Francisco, em Sergipe:

Quando Lampião esteve em Canindé, em janeiro de 1932, onde moravam pessoas da família Marques, Zé Baiano recebeu carta branca de Lampião para vingar-se do que fizeram com sua mãe. Ao prender Maria Marques, irmã do soldado que supliciara sua mãe, Zé Baiano decidiu deixá-la marcada para sempre e mandou que um morador chamado Zé Rosa fosse buscar um ferro de marcar gado. Zé Rosa tinha sido vaqueiro do finado coronel João Brito (João Fernandes de Brito). Trouxe o primeiro ferro que encontrou, o ferro utilizado no passado para marcar os bois de seu falecido patrão, que tinha as letras 'J-B', de João Brito. Além de Maria Marques, foram ferradas no mesmo dia outras duas mulheres, ambas ligadas também a soldados por casamento ou mancebia. Por fim, quando observaram que as letras do ferro - 'J-B' - eram as letras do seu nome, o cangaceiro decidiu levar o ferro como recordação de sua vingança, porém não há nenhum relato de fonte segura de que o tivesse utilizado outras vezes (Lima Irmão, 2014: 414). 
Inúmeros trabalhos sobre a violência e o banditismo no Nordeste destacam a figura de José Baiano conduzindo "um ferro de gado com as suas iniciais, destinado a marcar mulheres nas faces, coxas ou nádegas, desde que usassem cabelos ou vestidos curtos" (Mello, 2004: 162). É certo que muitas cangaceiras também foram vítimas em diversos confrontos, tendo sido, inclusive, decapitadas. Todavia, os rostos marcados com ferro em brasa tornaram-se emblemáticos da atuação de José Baiano em mulheres que possuíam relação com a polícia, como forma de represália ao espancamento de sua mãe por soldados: "apenas Anízia não tinha ligação direta com a polícia. Maria Marques era irmã do soldado Vicente (aquele que espancara a mãe de Zé-Baiano), Izaura era esposa do soldado Bilrinho e Natália esposa do soldado Maninho, que teria sido poupada (...) por causa de seu estado avançado de gestação" (Freitas, 2005: 201).

Maria Marques, Anízia e Izaura tiveram seus rostos marcados com as iniciais "JB" como forma de registrar em seus corpos que as ações praticadas contra os cangaceiros seriam revidadas. Segundo Ana Paula Freitas (2005), essas atrocidades demarcaram uma disputa psicológica entre cangaceiros e volantes: "os primeiros para mostrar as consequências de uma traição, e os segundos para mostrar o que aconteceria à mulher que quisesse enveredar pelos caminhos do cangaço. (...) A sertaneja vivia no meio de um fogo cruzado" (Freitas, 2005: 204). De acordo com a pesquisadora, tais ações evidenciam o domínio sobre o corpo das mulheres, sendo as mulheres no cangaço vistas como propriedade, muitas raptadas abruptamente.

Na verdade, embora parte considerável da fortuna crítica destaque frequentemente esse episódio retroalimentando o imaginário sobre o cangaço, torna-se curioso que ele seja utilizado para fabricar a imortalidade do cangaceiro José Baiano e, ao mesmo tempo, reforçar a dominação sobre os corpos femininos. Da leitura dos documentos existentes poucas são as informações sobre essas mulheres, apresentadas, muitas vezes, como coadjuvantes na épica do cangaço. Seus nomes, inclusive, aparecem de modo contraditório, sem um esboço das suas trajetórias antes, durante e após a mutilação dos corpos. Paradoxalmente, é inegável que Maria, Anízia e Izaura sobreviveram ao esquecimento em virtude de portarem em suas faces as marcas de um "evento crítico". Nosso intuito é analisar o modo como foram arquivadas e as tensões que ocultam/revelam quando (in)visibilizadas em diferentes exposições museológicas.

\section{Marcas de sangue em Quatro museus}

história do cangaço é traduzida nos diversos campos da arte e do patrimônio, em relei-
turas estéticas - na fotografia, no cinema, na música, na literatura, na xilogravura, no teatro, no artesanato, na moda (cf. Ferreira; Araújo, 2011) - e em exposições museológicas de 
diversas instituições brasileiras. ${ }^{1}$ Nosso intuito neste item é demonstrar as tensões em torno da musealização das lembranças e dos silêncios da trajetória de José Baiano e das mulheres por ele violentadas.

0 objetivo é reconhecer os diferentes registros do processo expositivo como possibilidades discursivas para a compreensão das pulsões expressivas dos responsáveis pela concepção das exposições museológicas. Trata-se de ação que dialoga com Cristina Bruno (1996) quando esta afirma a importância de analisar os aspectos constitutivos do processo de musealização e a natureza dos procedimentos inerentes à construção do discurso expositivo, captando os bastidores e cenas relacionadas às exposições.

Nesse sentido, é oportuno destacarmos as considerações de Mário Chagas (2006) ao afirmar que existe uma gota de sangue em cada museu, explicitando o potencial poético e político das narrativas museológicas. No caso das exposições sobre o cangaço - e aqui focalizadas no episódio de Canindé de São Francisco -, essa interpretação é relevante na medida em que as marcas de sangue reais se transformaram em discursos expográficos, acionando diversas expressões.

Além disso, é necessário reconhecer os argumentos de Frederico Pernambucano de Mello (2010) quando este avalia que os objetos do cangaço em coleções públicas e particulares: 1 - consistem em peças raras em virtude da repressão sofrida por seus usuários, no intuito de "abater os sinais de rebeldia que imantavam esses troféus a olhos oficiais e relegando praticamente ao vazio as vitrines dos museus sobre os movimentos sociais insurgentes de nossa história"; 2 - emanam de circunstâncias de "conflito sempre possível, com a perspectiva da morte violenta do usuário insinuando-se no cotidiano, o que as faz refertas de uma simbologia mística, exacerbada em profusão dos signos de defesa e rebate" (Mello, 2010: 20). Colaborando com esse entendimento, Mello apresenta o arrolamento do espólio de diversos cangaceiros, a exemplo do de José Baiano transcrito em 1936 pelo Correio de Aracaju e pela Gazeta de Alagoas:

Um chapéu de feltro cow-boy, com três correias contendo 37 medalhas, duas alianças e 28 botões, tudo de ouro. Nas medalhas existem as iniciais AN e os nomes Amor, Lembrança e Maroquinhas. Na frente do chapéu, pregada, uma chapa de ouro em forma de coração. Ainda em uma das correias existem outras medalhas com as inscrições: Amor de mãe e Souvenir, e duas libras esterlinas com os dizeres Verdade e Justiça, 27 anéis, sendo dois anelões, um brilhante grande, quatro anéis grandes com as iniciais JB, outro com pedras diversas e brilhantes pequenos. Uma caixa com cinco cordões de ouro, quatro cadeias de ouro com uma libra esterlina, uma santa, três barretes e outros pertences de senhora, uma corrente com um emblema maçônico de valor, tendo um brilhante incrustado. Dois parabelluns, uma mauser, três mosquetões, tendo 
16 moedas de prata na bandoleira, seis bornais, dois ferros de marcar com as iniciais JB, quatro punhais com cabo de prata e incrustações de ouro em um deles, seis cartucheiras, um facão, três chapéus, sendo um de couro (Mello, 2010: 218-219).

0 primeiro indício que encontramos da musealização de alguns desses objetos consistiu nos relatos de José Augusto Garcez (1958) quando descreveu o Museu Sergipano de Arte e Tradição, instalado em 1948 em Aracaju (SE). Fruto de coleção particular, uma das temáticas do acervo era o "Ciclo do cangaceiro", constituído por "embornais de pano e couro, cantil, chapéu e punhais que pertenceram aos bandidos: José Baiano e Lampião" (Garcez, 1958: 34). Atualmente as peças integram o acervo do Museu Histórico de Sergipe, em São Cristóvão (SE), e, ao serem expostas juntamente com outras peças representativas do cangaço, são obscurecidas pela força adquirida pelo mito Lampião. Os "dois ferros de marcar com as iniciais JB" não integram a coleção.

Outro indício consistiu em um texto do pesquisador Alfredo Bonessi (2015), intitulado "O ferro de Zé Baiano". Nele, o escritor afirma ter localizado o paradeiro de um dos ferretes do cangaceiro na exposição de longa duração do Museu Histórico Nacional, no Rio de Janeiro, informando que o objeto se encontrava integrado a um conjunto de peças de fins do século XIX relacionadas ao período da escravidão no Brasil, deslocado de seu contexto original.

No Museu Histórico Nacional identificamos um ferro de marcar com as iniciais "JB" integrando o módulo "Riqueza e escravidão". Neste módulo, dois marcadores foram afixados em um painel vermelho, juntamente com instrumentos de tortura datados do século XIX (vira-mundos, libambos, gargalheiras, anjinho e algemas), além de um tronco castigo, em madeira. Todavia, não existe alusão na expografia que indique esse objeto como integrante do ciclo do cangaço ou como relacionado a José Baiano (Figura 1).

Figura 1: Ferros de marcar.

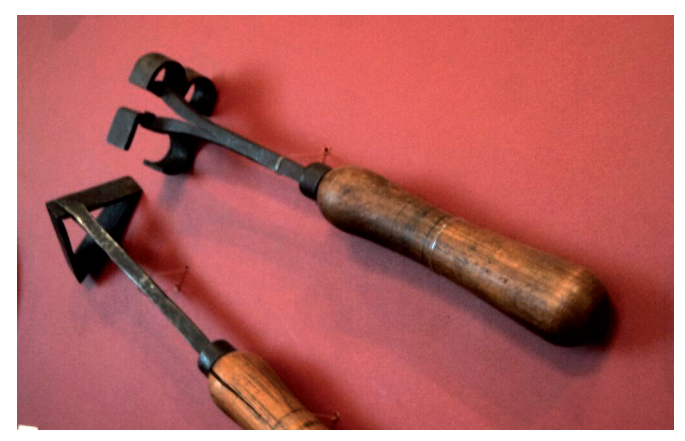

Acervo do Museu Histórico Nacional, Ibram/MinC, autorização de uso de imagem n. ${ }^{\circ}$ 024/2015. Foto: Moema Alves, 2015. 
O mesmo silêncio se estende à documentação museológica. Na seção de arquivo fotográfico, a ficha relacionada aos marcadores é assim descrita: "Escravos. Instrumentos de suplício. Ferros de marcar escravos, dos tipos existentes no MHN". Na ficha de identificação do acervo, o ferro é apresentado com as seguintes informações: "Ferro para marcar escravos com cabo torneado em madeira de tonalidade castanho clara. A referida peça traz em seu ferro fundido as iniciais JB. Cabo apresentando rachadura em uma das extremidades". Também informa que o mesmo possui $27 \mathrm{~cm}$ de comprimento, 5,5 cm de largura e $4 \mathrm{~cm}$ de altura e indica como procedência a compra de José Joaquim Cardoso, seguida por uma interrogação. O local não foi informado e a data do objeto é apresentada como sendo do século XIX.

A leitura dessa ficha com diversos campos em branco, reticências e interrogações, apresenta as incertezas em torno da origem e função do objeto. Todavia, embora marcadores como esses também tenham sido utilizados para castigar pessoas escravizadas no Brasil do século XIX (cf. Pericás, 2010), as iniciais "JB" suscitam dúvidas com relação a essa datação e procedência, a exemplo dos questionamentos de Alfredo Bonessi (2015) que a vinculam à trajetória do cangaço e a José Baiano.

Embora possa ter sido apenas uma coincidência, as iniciais fundidas no marcador contribuíram para que a expografia acionasse outras violências possíveis, para além das empreendidas contra os negros e negras escravizados até o século XIX. Por outro lado, a peça sendo reconhecida como espólio de José Baiano, remeteria às violências instituídas no início do século XX contra as mulheres e evocaria o cangaço como outra narrativa a ser explorada. É por isso que Mário Chagas (2003) reconhece que os museus são devoradores e, do ponto de vista museológico, preservar também pode implicar uma ação contra a vida. Para tanto, utiliza como exemplo das refuncionalizações e ressignificações dos objetos nos museus a trajetória do vestido de Maria Bonita, que, mesmo preservado no Museu Histórico Nacional, permanecia nos "silêncios da história", situação que pode ser similar à do marcador ali exposto:

Em 1992, ao tentar remontar a trajetória desse vestido, Frederico Pernambucano de Melo da Fundação Joaquim Nabuco (PE), recebeu a informação que ele teria sido doado ao Museu Histórico Nacional nos anos setenta. Depois de dois anos, por um golpe de sorte, a peça de indumentária foi reencontrada no Museu, sem nenhum registro documental, incluída como um trapo inútil num lote para descarte (Até aquela data o vestido não havia recebido nenhum tratamento documental e como não estava registrado não se cogitava sequer de um processo de baixa). Recuperou-se, com a ajuda do estudioso pernambucano, a trajetória do vestido sobrevivente, que um dia deu contorno ao corpo da cangaceira. Ele fora doado ao Museu pela atriz comediante Nádia Maria, que o recebera de seus familiares que, por sua vez, haviam-no recebido do repórter Melquiades da Rocha, que o recebera do referido aspirante Francisco 
Ferreira Melo. (...) Esses fluxos e refluxos de significados e funções, envolvendo em alguns casos as esferas pública e privada, parecem ser mais frequentes do que se imagina, ainda que os museus de maneira geral operem com a hipótese da eternização dos bens culturais nos seus domínios (Chagas, 2003: 38-39).

Diferentemente da exposição no Museu Histórico Nacional, onde a trajetória de José Baiano aparece silenciada e pode ser presumida graças às iniciais fundidas no ferro de marcar, no Museu do Cangaço localizado no Povoado de Alagadiço, em Frei Paulo (SE), ela é um dos principais sustentáculos da narrativa. Criado em 2008 pelo colecionador e escritor Antônio Porfírio de Matos Neto, o museu possui seis salas e se apresenta nos moldes de um gabinete de curiosidades dedicado integralmente ao cangaço. Seu acervo é composto por utensílios domésticos, moedas, armamentos, imagens sacras, pinturas, fotografias, esculturas e uma biblioteca.

o colecionador criou o museu com o objetivo de promover a memória do cangaço naquela região, especialmente da atuação de Lampião que esteve no povoado por quatro vezes e de José Baiano que ali residiu e foi assassinado em 7 de junho de 1936: "Baiano chegou a ser, entre os anos de 1934 e 1936, um dos mais fortes agiotas do sertão e de parte da zona dos canaviais de Sergipe", tendo terminado "violentamente seus dias, com todo o grupo, em cilada urdida por tomador a quem o uso crescente de álcool fizera cair em insolvência" (Mello, 2004: 72).

Estas questões estão também registradas no livro Lampião e Zé Baiano no Povoado Alagadiço, de Antônio Porfírio de Matos Neto (2009). Sobrinho de Pedro Guedes, um dos seis homens que exterminaram o cangaceiro e seu bando, Antônio Porfírio recebeu do tio como herança alguns dos objetos que estavam com José Baiano no momento de sua morte. Além disso, reuniu peças que foram encontradas na Toca da Onça, em Alagadiço. Do espólio de José Baiano destaca que possui em sua coleção: um cantil, um mosquetão, um bornal, um punhal, um parabellum e um ferro de marcar com as iniciais "JB" (Figura 2).

Apesar de não existir uma expografia, nem identificação das peças, o ferro de marcar atribuído ao espólio de José Baiano ocupa uma posição de destaque na mesa que serve como suporte para a exposição. A partir dele o mediador reconta a trajetória do cangaço e a história do povoado, relembrando a presença de Lampião, de José Baiano e outros cangaceiros naquela região, embora não existam registros de que outras mulheres foram marcadas como ocorreu em Canindé. Na exposição museológica as mulheres violentadas não são representadas, sendo apenas citadas para justificar a existência da peça e a crueldade do cangaceiro ali monumentalizado por uma série de conflitos que culminaram com sua morte em Lagoa Nova, no Povoado de Alagadiço.

Para além da musealização dos ferros de marcar, que evoca a persona do "cangaceiro ferrador" em detrimento das mulheres vitimizadas, existem exposições construídas sob outra 
Figura 2: Ferro de marcar.

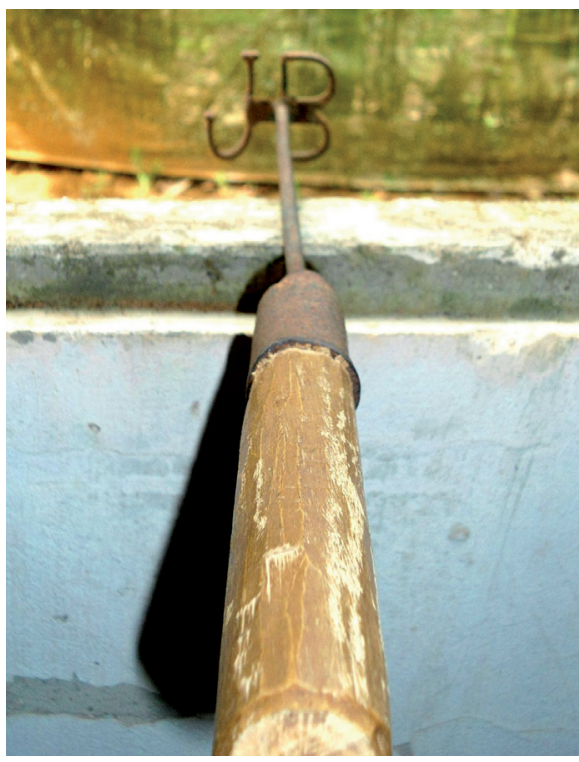

Acervo do Museu do Cangaço, Frei Paulo-SE. Foto: Clovis Britto, 2015.

perspectiva, a exemplo da apresentada pelo Memorial de Sergipe, da Universidade Tiradentes. Criado em 1998 e sediado em Aracaju (SE), o Memorial possui mais de 20 mil peças e está organizado em 12 salas temáticas: Universidade Tiradentes, Arqueologia: José Augusto Garcez, Formação de Sergipe, Arqueologia Subaquática, Personalidades Sergipanas, Segunda Guerra Mundial, Rosa Moreira Faria, Marcas do Homem Sergipano, Cultura Popular, Meios de Comunicação, Estudos e Pesquisas, e Cangaço.

A "Sala Cangaço" abriga o acervo da pesquisadora Vera Ferreira, neta de Maria Bonita e Lampião. Composta por diversos objetos pertencentes aos líderes do cangaço, a expografia também apresenta painéis com a reprodução de fotografias e outros documentos relacionados à trajetória dos cangaceiros. É evidente uma preocupação em destacar a presença feminina no cangaço. Com o intuito de retirar as mulheres dos "silêncios" também foi musealizado o episódio de Canindé a partir de uma foto do rosto marcado de Maria Marques já idosa com a seguinte legenda: "Maria Marques, uma das mulheres marcadas a ferro pelo cangaceiro Zé Baiano" (Figura 3).

Embora a fotografia do rosto mutilado de Maria Marques provoque uma série de reações, ao ser inserida em um painel de destacada proporção ela, de algum modo, subverte a sua posição na história do cangaço. A estratégia expográfica, no mesmo sentido, valoriza o protagonismo feminino no movimento ao destinar um espaço a fotos de mulheres que 
Figura 3: Foto de Maria Marques reproduzida no Memorial de Sergipe.

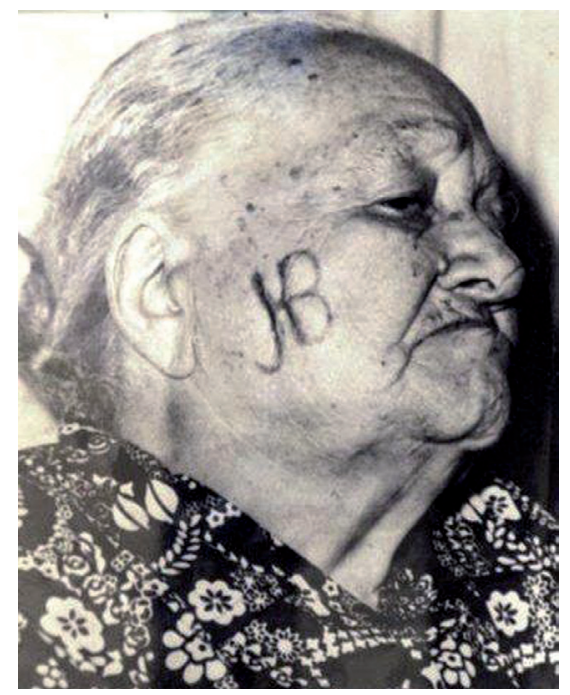

In: Lima Irmão, 2014.

participaram distintamente do cangaço. Ao inserir a imagem de Maria Marques ao lado das fotos das cangaceiras Dadá, Aristéia e Maria Bonita, por exemplo, a exposição não hierarquiza a participação feminina. Por outro lado, a opção pelas imagens de Maria Marques e das cangaceiras na velhice também contribui para uma reflexão geracional e de gênero, demonstrando que elas sobreviveram a uma configuração hostil e se tornaram "guardiãs da memória" do cangaço (Gomes, 1998).

Tal situação é evidenciada na expografia do Museu do Cangaço de Triunfo (PE), que dedicou um espaço para a apresentação de fotografias das mulheres ferradas por José Baiano. Fundado em 1975, o museu é dedicado à memória do cangaço com cerca de 500 peças como fotografias, armamentos e indumentárias. Os argumentos apresentados com relação ao Memorial de Sergipe também podem ser aqui estendidos. Todavia, nesta exposição as memórias sobre as mulheres violentadas por José Baiano são evidenciadas em um espaço próprio, a partir de três fotografias emolduradas: duas fotos do rosto marcado de Maria Marques (uma jovem e outra idosa) e uma foto de Olindina Marques, identificada como vítima do episódio de Canindé (Figura 4).

Nesse caso, é importante reconhecer as narrativas conflituosas em torno da identificação dessas mulheres. Conforme constatamos anteriormente, existem divergências em torno dos nomes das vítimas do cangaceiro ferrador. A fortuna crítica sobre o cangaço destaca Maria Marques, Anízia e Isaura. 0 Museu do Cangaço de Triunfo identifica Olindina Marques e existem trabalhos que informam os nomes de Antônia Marques e Balbina da Silva. Além de 
Figura 4: Foto de mulher com o rosto marcado reproduzida no Museu do Cangaço de Triunfo.

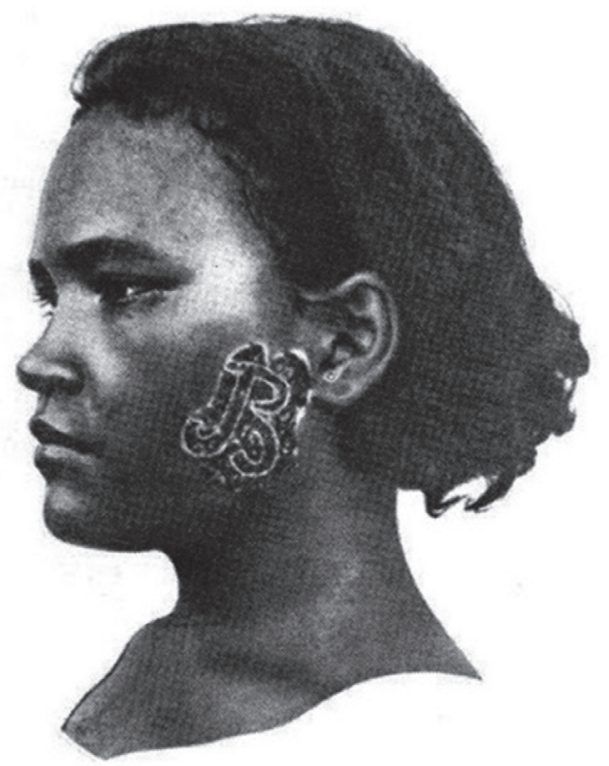

In: Mello, 2004.

fornecer os nomes das mulheres, a exposição as associa a José Baiano, informando a data da violência e o local onde ocorreu, sem apresentar maiores informações sobre essas e outras vítimas do cangaceiro.

Apesar de destacar as mulheres, ao selecionar quais fotografias seriam expostas e ao esquecer outras personagens violentadas pelo cangaceiro, a exposição contribui para a instituição de outros silêncios. Exemplo disso são os não-ditos em torno da cangaceira Lidia, companheira de José Baiano, violentamente espancada pelo parceiro até a morte. Tais problematizações contribuem para que visualizemos o poder masculino sobre os corpos e as vidas das mulheres no cangaço e, ao mesmo tempo, como a musealização se reveste de um exercício de poder.

A análise das trajetórias da musealização das mulheres ferradas em Canindé contribui para problematizarmos a relação entre memória, museus e "eventos críticos", além dos desafios em torno da manipulação dessas narrativas. Do mesmo modo, evidencia as diversas potencialidades - entre silêncios e marcas - em torno da exposição de um mesmo fato. Esses recortes relacionados à representação do cangaço nos museus brasileiros contribuem para o reconhecimento de questões como a importância da pesquisa e da ética nos museus, juntamente com as possibilidades polissêmicas a serem utilizadas na construção das exposições museológicas. 


\section{NotA}

1 São exemplos de instituições museológicas que possuem acervos relacionados ao cangaço: Museu Histórico Nacional, no Rio de Janeiro/RJ; Museu do Cangaço/Fundação Cultural Cabras de Lampião em Serra Talhada/PE; Museu do Cangaço e da Cidade de Triunfo, em Triunfo/PE; Museu-Casa de Maria Bonita, em Paulo Afonso/SE; Museu do Cangaço, no Povoado de Alagadiço em Frei Paulo/SE; Memorial da Universidade Tiradentes, em Aracaju/SE; Museu Histórico de Sergipe, em São Cristóvão/SE; Museu Estácio de Lima, em Salvador/BA; Museu do Instituto Histórico e Geográfico de Alagoas, em Maceió/AL; e Museu do Sertão, em Piranhas/AL.

\section{REFERÊNCIAS BIBLIOGRÁFICAS}

ARAÚJO, Antônio Amaury Corrêa de. Lampião, as mulheres e o cangaço. São Paulo: Traço, 2012.

BONESSI, Alfredo. O ferro de Zé Baiano. Disponível em: http://cariricangaco.blogspot.com.br/2015/05/0-ferro-de-ze-baiano-poralfredo-bonessi.html Acesso em: 30 jul. 2015.

BRUNO, Maria Cristina Oliveira. Museologia: a luta pela perseguição ao abandono. Tese (Livre-Docência), Museu de Arqueologia e Etnologia, Universidade de São Paulo, 2000.

Formas de humanidade: concepção e desafios da musealização. Cadernos de Sociomuseologia, n. ${ }^{\circ}$ 9, 1996.

CHAGAS, Mário de Souza. Há uma gota de sangue em cada museu: a ótica museológica de Mário de Andrade. Chapecó, SP: Argos, 2006.

A imaginação museal: museu, memória e poder em Gustavo Barroso, Gilberto Freyre e Darcy Ribeiro. Tese (Doutorado em Ciências Sociais), Universidade do Estado do Rio de Janeiro, 2003.

CUNHA, Eneida Leal. A "Casa Jorge Amado". In: SOUZA, Eneida Maria de; MIRANDA, Wander Mello (Orgs.). Arquivos literários. São Paulo: Ateliê Editorial, 2003.

DAS, Veena. Critical events. An anthropological perspective on contemporary India. Delhi: Oxford University Press, 1995.

DESVALLÉES, André; MAIRESSE, François (Eds.). Conceitos-chave de Museologia. Tradução e Comentários de Bruno Brulon Soares e Marília Xavier Cury. São Paulo: Comitê Brasileiro do Conselho Internacional de Museus: Pinacoteca do Estado de São Paulo: Secretaria do Estado da Cultura, 2013.

FERREIRA, Vera; ARAÚJO, Germana Gonçalves de (Orgs.). Bonita Maria do Capitão. Salvador: EDUNEB, 2011.

FREITAS, Ana Paula Saraiva de. A presença feminina no cangaço: práticas e representações (1930-1940). Dissertação (Mestrado em História), Universidade Estadual Paulista Júlio de Mesquita Filho, 2005.

GARCEZ, José Augusto. Realidade e destino dos museus. Aracaju: Livraria Regina, 1958.

GOMES, Ângela de Castro. Nas malhas do feitiço: o historiador e os encantos dos arquivos privados. Estudos Históricos, Rio de Janeiro, n. 21, 1998.

LIMA IRMÃO, José Bezerra. Lampião: a raposa das caatingas. Salvador: JM Gráfica \& Editora, 2014. 
MATOS NETO, Antônio Porfírio de. Lampião e Zé Baiano no Povoado Alagadiço. Aracaju: Edição do Autor, 2009.

MELLO, Frederico Pernambucano de. Estrelas de couro: a estética do cangaço. São Paulo: Escrituras, 2010.

Guerreiros do sol: violência e banditismo no Nordeste do Brasil. São Paulo: A Girafa, 2004.

PERICÁS, Luiz Bernardo. Os cangaceiros: ensaio de interpretação histórica. São Paulo: Boitempo, 2010.

PERROT, Michelle. As mulheres ou os silêncios da história. Bauru, SP: EDUSC, 2005.

QUEIROZ, Marijara Souza. Museu, memória e a morte: um estudo a partir da coleção de quadros de cabelos da Fundação Instituto Feminino da Bahia. Dissertação (Mestrado em Artes Visuais), Universidade Federal da Bahia, 2014.

SELIGMANN-SILVA, Márcio. Testemunho da Shoah e literatura. X Jornada Interdisciplinar sobre o Ensino da História do Holocausto, São Paulo, 2009.

Narrar o trauma - a questão dos testemunhos de catástrofes históricas. Psicologia Clínica, Rio de Janeiro, v. 20, n. ${ }^{\circ} 1,2008$.

SILVA, Telma Camargo da. Musealização de eventos críticos: análise da tensão entre múltiplas narrativas da dor. XXXIV Encontro Anual da ANPOCS, Caxambu, 2010.

; SOUZA, Maria Luiza Rodrigues; ECKERT, Cornélia. Apresentação. Sociedade e Cultura, Goiânia, v. 14, n. ${ }^{\circ} 2,2011$.

TAMASO, Izabela. A expansão do patrimônio: novos olhares sobre velhos objetos, outros desafios... Sociedade e Cultura, Goiânia, v. 8, n. 2, jul/dez 2005. 